\title{
Multi-scale reinforcement of epoxy composites - Use of carbon fibre fabrics coated with an epoxy binder containing MWCNTs for improved interlaminar fracture resistance
}

\section{DOI:}

10.1016/j.compositesb.2018.11.100

\section{Document Version}

Accepted author manuscript

Link to publication record in Manchester Research Explorer

\section{Citation for published version (APA):}

Patel, K., Potluri, P., Yousaf, Z., \& Wilkinson, A. (2019). Multi-scale reinforcement of epoxy composites - Use of carbon fibre fabrics coated with an epoxy binder containing MWCNTs for improved interlaminar fracture resistance. Composites. Part B: Engineering, 165, 109-119. https://doi.org/10.1016/j.compositesb.2018.11.100

\section{Published in:}

Composites. Part B: Engineering

\section{Citing this paper}

Please note that where the full-text provided on Manchester Research Explorer is the Author Accepted Manuscript or Proof version this may differ from the final Published version. If citing, it is advised that you check and use the publisher's definitive version.

\section{General rights}

Copyright and moral rights for the publications made accessible in the Research Explorer are retained by the authors and/or other copyright owners and it is a condition of accessing publications that users recognise and abide by the legal requirements associated with these rights.

\section{Takedown policy}

If you believe that this document breaches copyright please refer to the University of Manchester's Takedown Procedures [http://man.ac.uk/04Y6Bo] or contact uml.scholarlycommunications@manchester.ac.uk providing relevant details, so we can investigate your claim.

\section{OPEN ACCESS}


Multi-scale Reinforcement of Epoxy Composites - Use of Carbon Fibre Fabrics Coated with an Epoxy

Binder Containing MWCNTs for Improved Interlaminar Fracture Resistance

\author{
Kinjalkumar Patel, Prasad Potluri, Zeshan Yousaf, Arthur Wilkinson* \\ North West Composites Centre, School of Materials, \\ University of Manchester, Manchester M13 9PL, UK.
}

*Corresponding author. Tel.: +44 (0)161 3065691. E-mail: Arthur.Wilkinson@manchester.ac.uk

\begin{abstract}
Epoxy multi-scale composites were produced using woven carbon fibre (CF) fabric coated with an aqueous dispersion of multiwall carbon nanotubes (MWCNT) in an epoxy binder. The reinforcement of the CF-epoxy interface increased inter-laminar fracture toughness (ILFT) in mode I by $234 \pm 13 \%$ and in mode II by $106 \pm 2 \%$. These increases were attributed to both the binder, which alone (cured without MWCNT) increased ILFT by $87 \pm 8 \%$ for mode I and $40 \pm 10 \%$ for mode II, and to MWCNT pull-out and fracture. The uncured binder caused plasticisation of the matrix, which was addressed somewhat by crosslinking of the binder and further by the addition of MWCNTs.
\end{abstract}

Keywords Carbon fibres; Carbon nanotubes; Polymer-matrix composites (PMCs); Delamination; Fracture toughness.

\title{
1 Introduction
}

Multi-scale (or hierarchical) laminate composites in which nanoscale reinforcing particles, such as multiwall carbon nanotubes (MWCNTs), are employed together with typical microscale reinforcing fibres [1] offer opportunities to significantly improve the matrix-dominated properties of conventional laminate composites [2]. Initial research focused mainly on dispersion of MWCNTs into matrix resins using techniques such as calendaring, milling, shear mixing, high-pressure homogenization, and sonication [1, 3]. However MWCNTs when dispersed in resins tend to reaggregate [4] which, together with the very large increases in resin viscosity which occur upon addition of only a few volume \% of MWCNTs [5, 6], can cause significant problems for infusion composite processing [7]. To avoid the problems associated with adding MWCNTs to the full matrix several groups have reported techniques designed to concentrate the MWCNTs at the matrix-fibre interface [810]. Grafting of MWCNTs onto the surface of the fibre reinforcement using techniques such as chemical vapour deposition [8] is reported to be an effective, if complex, method of providing nanoscale reinforcement of the fibre-matrix interface. Simpler approaches utilised in creating MWCNT-reinforced interfaces include spraying of MWCNT dispersions onto fibre reinforcements prior to processing [8], although only relatively low levels of nanotubes could be applied. Herceg et al [10] described a route of wet powder impregnation followed by drum winding for preparing CF pre-pregs with very high levels of MWCNTs (up to 6.1 vol.\%) which produced composites with large increases in electrical conductivity and interlaminar fracture toughness, ILFT (discussed later). As discussed, MWCNTs can be introduced to fibre reinforced composites using a range of different approaches and each has its advantages and disadvantages. In this study, we investigate multi-scale composites produced using carbon fibre (CF) fabrics coated with MWCNTs using a relatively quick and easy spreading process of aqueous epoxy dispersions to create a toughening layer at the fibre-matrix interface. The main aim was to improve the ILFT of laminar CF-epoxy composites using a toughening epoxy-based coating and MWCNTs. The objectives were: to develop a simple coating technique to bind the MWCNTs onto the surface 
of CF fabrics prior to the preparation of multi-scale composites; to study the effects of the uncured and cured coatings on the mode I and mode II ILFT of the composites, and to study the effects of introducing MWCNT to the fibre-matrix interface.

\section{Materials}

The base CF fabric used in all composites was a 5-harness satin weave with an areal density of $380 \mathrm{gm}^{-2}$ (Sigmatex UK). Five types of CF fabrics were used to produce laminates, the as-received CF fabric (coded as A) and four types of coated fabrics, namely: coated with neat (non-curable) epoxy binder containing no curing agent (coded UB); coated with a 1 wt.\% dispersion of MWCNTs in non-curable binder (UBC); coated with curable epoxy binder (B); and fabric coated with a 1 wt.\% MWCNT dispersion in curable binder (BC). The epoxy resin matrix system used was a mixture (100:35) of Araldite LY 564, a low molar mass diglycidyl ether of bis-phenol A (DGEBA)/ butane diol-diglycidyl ether resin blend of equivalent weight 165 \pm 5 g/eq., and Aradur 2954 (2, 2'dimethyl-4.4'-methylenebis (cyclohexylamine)) curing agent (both Huntsman Advanced Materials). The MWCNTs used were NC7000 (Nanocyl), industrial grade MWCNTs reported by the manufacturer to have an average diameter and length of $9.5 \mathrm{~nm}$ and $1.5 \mu \mathrm{m}$, respectively. The average diameter of NC7000 has been confirmed as $9.5( \pm 1.81) \mathrm{nm}$ using TEM [11]. The binder used to coat the UB and B fabrics and to bind the MWCNTs onto the UBC and BC fabrics was an aqueous dispersion of a solid DGEBA epoxy resin, EPI-REZ 3522-W-60 (Hexion), reported by the manufacturer to contain $59.5 \pm 1$ wt.\% particles of $1-3 \mu \mathrm{m}$ in size. The resin is a medium molar mass epoxy of $616 \pm 1 \mathrm{~g} / \mathrm{eq}$. epoxy equivalent weight with a glass transition temperature and melting point of 40 and $65^{\circ} \mathrm{C}$ as measured by DSC. This dispersion is marketed by the manufacturer as a size for carbon fibres for which it is often used in its uncrosslinked state, as in part of this study. Two fabrics were also coated with a curable binder system for which the curing agent used was, as recommended by the resin manufacturer, a mixture of dicyandiamide (dicy) and 2-methylimidazole (2MI) [12]; this was prepared (per 100 parts binder) by dissolving 1.2 parts of dicy and 0.15 parts of $2 \mathrm{MI}$ into 21 parts of distilled water at $70{ }^{\circ} \mathrm{C}$.

\section{Sample preparation}

\subsection{Dispersion of MWCNTs into the binder}

As-received MWCNTs were mixed with the binder; firstly using a mechanical stirrer for 15 minutes followed by high-shear mixing using a Silverson L5M-A laboratory-scale homogeniser operated at 5000 rpm for 2 hours. The quantity of MWCNTs in the dispersion was $1 \mathrm{wt} . \%$ and an ice bath was used to control the temperature of the mixture between $20-30{ }^{\circ} \mathrm{C}$. This addition produced a high viscosity gel-like MWCNT-binder dispersion and preliminary experiments had shown that attempts to use MWCNT levels $\geq 2 \mathrm{wt}$.\% caused problems in spreading the dispersion onto the CF fabric.

\subsection{Coating of the CF fabric}

The CF fabric was cut into plies of $20 \mathrm{~cm}$ x $20 \mathrm{~cm}$ and then coated with either neat binder or the dispersion of MWCNT-binder using a K-control spreading coater (RK Prints Ltd). This coater can be operated at web speeds between $2-15 \mathrm{~m} / \mathrm{min}$ and gives wet film thicknesses between 4-200 $\mu \mathrm{m}$. Following preliminary experiments, varying the web speed to obtain a uniform thickness of the unfilled binder and of the high viscosity MWCNT dispersions on the surface of the CF fabric, the coater was subsequently operated at $6 \mathrm{~m} / \mathrm{min}$. Fabrics were coated using a meter bar which gives a nominal wet coating thickness of $6 \mu \mathrm{m}$ and were subsequently dried overnight in an oven at $50{ }^{\circ} \mathrm{C}$. The weight $\%$ of neat binder or MWCNT-binder dispersion obtained after drying 
were measured at $6.5 \pm 0.4$ wt.\% and $6.7 \pm 0.5$ wt.\%, respectively. Figure 1 shows typical photographs of the asreceived (A) and a binder-coated fabric (UB), showing the coating applied evenly over the surface.
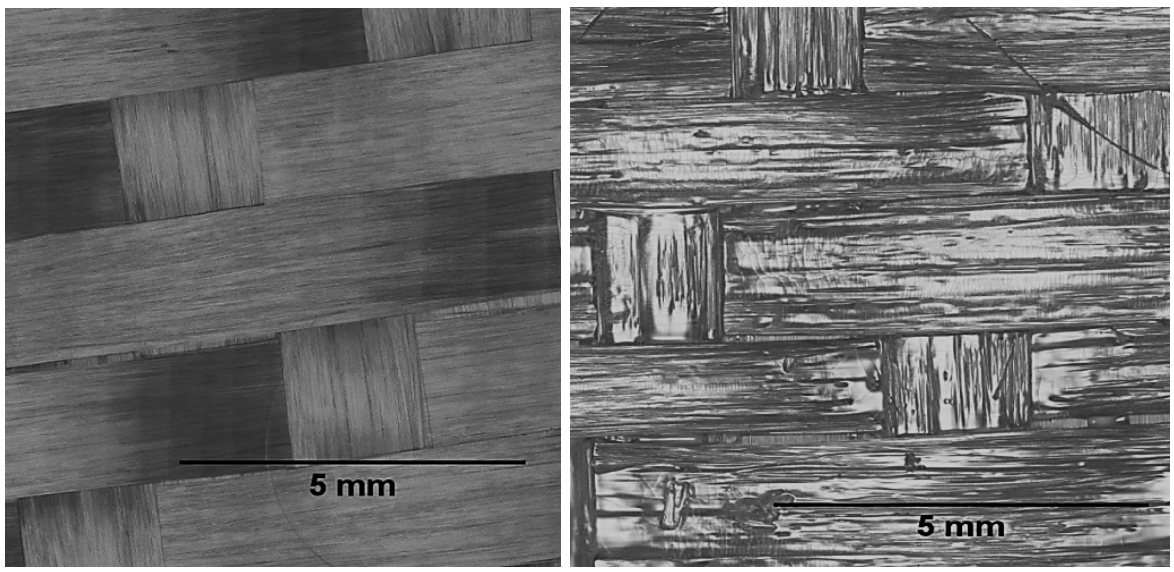

Figure 1. Typical images of the as- received A-fabric (left) and the neat-binder coated UB-fabric (right).

\subsection{Fabrication of the specimens}

For an initial processing study (to assess the effect of using coated fabrics), flat panels of CF - epoxy composites of nominal thickness $3.25 \mathrm{~mm}$ were prepared from the A, UB and B fabrics using resin infusion (RI) at room temperature. During preparation, 8 layers of each fabric were vacuum-bagged on a flat aluminium mould plate followed by RI; where resin flows from an inlet to an exit connected to a vacuum pump. Prior to RI, the epoxy resin system (100:35 by weight, resin:hardener) was mechanically-stirred (15 min at $500 \mathrm{rpm}$ ) than degassed for 30 min under vacuum. The infusion rate of the resin was controlled using a Hoffman clip to ensure complete wetting of the CF fabric. After completion of RI, samples were oven-cured at $80{ }^{\circ} \mathrm{C}$ for 1 hour followed by demoulding and post curing at $140{ }^{\circ} \mathrm{C}$ for 8 hours in an oven.

As a consequence of the results from this initial processing study (discussed in section 5.1), the specimens for the experimental procedures (described in sections 4.1 to 4.4) were taken from laminates produced using a hybrid RI-hot press process which is also described in section 5.1. Using this hybrid process, specimens for the inter-laminar fracture toughness (ILFT) tests were prepared with a PTFE starter film of $12 \mu \mathrm{m}$ thickness (A6000, Aerovac) embedded in the mid-plane, which simulates an initial delamination. The small specimens required for matrix digestion and dynamic mechanical thermal analysis (DMTA) were cut from the remainders of the ILFT sample plates.

\section{Experimental procedures}

Composite samples were tested firstly for fibre volume fraction using matrix digestion. Glass transition temperature $\left(\mathrm{T}_{\mathrm{g}}\right)$, mechanical damping and dynamic storage modulus data were determined using dynamic mechanical thermal analysis (DMTA). Mode I and mode II ILFT tests were carried out using dual cantilever beam (DCB) and 4 point end-notched flexure (4ENF) specimens, respectively. Each test was conducted on specimens from at least two panel samples. Therefore the \pm standard deviations reported after the mean values in the results tables and in the text reflect property variations; both panel-to-panel and specimen-to-specimen within the panels. 


\subsection{Fibre volume fraction}

The volume fractions of the carbon reinforcement, matrix and voids within the composites were determined by removing the epoxy resin matrices by acid digestion, following ASTM 3171 - procedure B which describes matrix digestion using sulphuric acid and hydrogen peroxide. Filtering out of solids was carried out under vacuum using a Whatman 934-AH glass microfibre filter in a Gooch crucible. This filter has a nominal particle retention of $1.5 \mu \mathrm{m}$ and the intention was to retain the CF. Although some retention of MWCNTs cannot be ruled out, the maximum quantity of nanotubes in the solids was calculated to be $\approx 0.45$ wt. $\%$ and so any errors were considered negligible. The data reported are the means of at least three measurements.

\subsection{DMTA}

Dynamic storage modulus $\left(\mathrm{E}^{\prime}\right)$ and damping factor $(\tan \delta)$ were determined in dual cantilever bending mode using a Perkin Elmer DMA 8000 instrument. Rectangular specimens (40 x $10 \mathrm{~mm}$ ) were tested at $1 \mathrm{~Hz}$ from 30 ${ }^{\circ} \mathrm{C}$ to $250{ }^{\circ} \mathrm{C}$ at a heating rate of $10{ }^{\circ} \mathrm{C} \mathrm{min}^{-1}$. The data reported are the means of at least five measurements.

\subsection{Mode I ILFT}

Critical strain-energy release rate, $\mathrm{G}_{\mathrm{IC}}$, data in mode I was determined according to ASTM D5528 [13]; in which mode I crack opening occurs due to loading applied perpendicular to the plane of delamination using pianohinges fitted to the end of a DCB specimen. Specimens (cut to $140 \mathrm{~mm}$ x $20 \mathrm{~mm}$ using a Benetec Slida 7000 Manual Sliding Cutter) had their side faces polished, painted white and were then marked from the edge of the insert film with vertical lines every $1 \mathrm{~mm}$ up to $50 \mathrm{~mm}$ to facilitate accurate measurement of crack length by visual observation using an image magnifier. Tests were carried out on an Instron 5969 universal testing machine equipped with a $10 \mathrm{kN}$ load cell. $\mathrm{G}_{\mathrm{IC}}$ data was calculated by modified beam theory (MBT) using equation 1.

$$
G_{I C}=\frac{3 P \delta}{2 b(a+I \Delta I)}
$$

Where, $\mathrm{P}$ is the applied load, $\delta$ displacement, b specimen width, a crack length and $\mathrm{I} \Delta \mathrm{I}$ is calculated using the compliance calibration method as defined in the standard. In accordance with ASTM D5528 [13], three methods were used to determine values of $\mathrm{G}_{\mathrm{IC}}$ at the initiation of delamination; visual observation, onset of non-linearity and $5 \%$ offset/maximum load (giving $\mathrm{G}_{\mathrm{IC}-\mathrm{Vis}}, \mathrm{G}_{\mathrm{IC}-\mathrm{NL}}$ and $\mathrm{G}_{\mathrm{IC}-\mathrm{Max}}$, respectively). Following initiation of delamination propagation values, $\mathrm{G}_{\mathrm{IC}}$-Prop, were determined as a function of crack length a. The data reported are the means of at least five measurements.

\subsection{Mode II ILFT}

Specimens for the 4ENF test (140 mm x $20 \mathrm{~mm}$ ) were prepared and tested using the methods described by Kuwata and Hogg [14]. The side faces of the specimens were polished, painted white and then marked from the edge of the insert film with vertical lines every $1 \mathrm{~mm}$ up to $40 \mathrm{~mm}$ to facilitate accurate measurement of crack length by visual observation using an image magnifier.

Four-point bend tests (Figure 2) were carried out on an Instron 5969 equipped with a $10 \mathrm{kN}$ load cell. The diameter of the support beam rollers and loading noses was $10 \mathrm{~mm}$ and the distances between them were 100 $\mathrm{mm}$ and $60 \mathrm{~mm}$, respectively. The speed of the cross-head for all tests was $0.5 \mathrm{~mm} / \mathrm{min}$. Following pre-cracking 
[14], specimens were re-loaded at $0.5 \mathrm{~mm} / \mathrm{min}$ and the load and displacement were recorded up to $40 \mathrm{~mm}$ crack length. From the data obtained $\mathrm{G}_{\mathrm{IIC}}$ was calculated using equation 2.

$$
G_{I I C}=\frac{P^{2} m}{2 b}
$$

Where, $\mathrm{P}$ is the applied load, $\mathrm{b}$ is the width of the specimen and $\mathrm{m}$ is the gradient from a compliance curve plotted according to MBT as defined in the method [14]. As in the mode-I tests, values of $\mathrm{G}_{\mathrm{IC}-\mathrm{Vis}}, \mathrm{G}_{\mathrm{IC}-\mathrm{NL}}, \mathrm{G}_{\mathrm{IC}-}$ Max and $\mathrm{G}_{\text {IC-Prop }}$ were determined. The data reported are the means of at least five measurements.

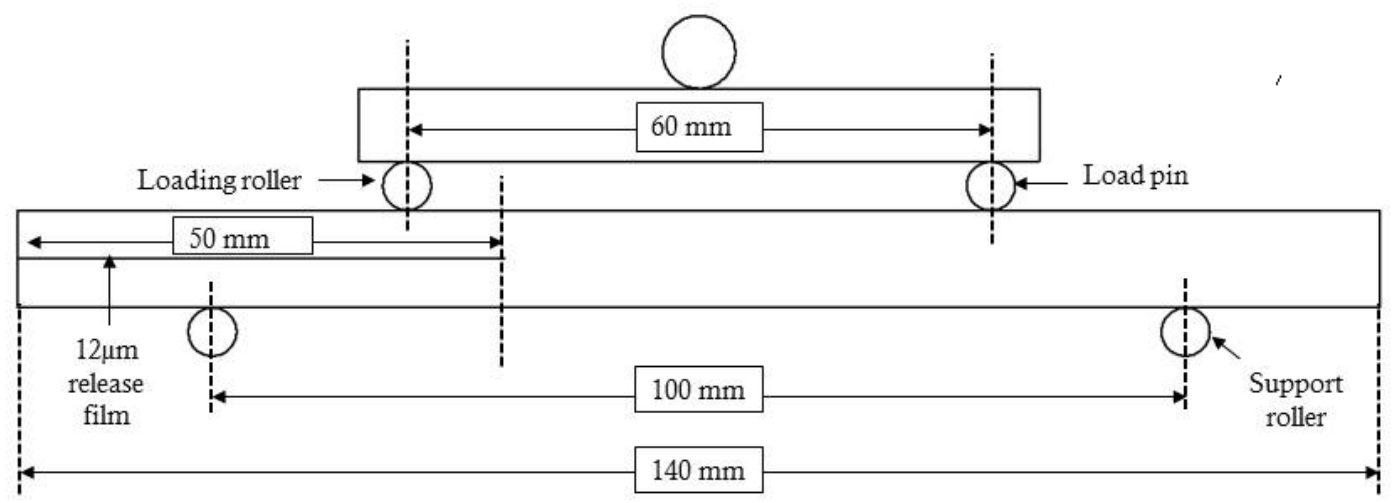

Figure 2. Test configuration for the four point end-notched flexural (4ENF) ILFT test.

Table 1. Volume fraction data from matrix digestion tests for composites produced by RI using as-received fabric (A) and two types of coated fabrics: non-curable binder (UB); 1 wt.\% MWCNTs in non-curable binder (UBC).

\begin{tabular}{|c|c|c|c|}
\hline \multirow{3}{*}{ Composite } & CF Reinforcement & Matrix & Voids \\
\hline & \multicolumn{3}{|c|}{ (epoxy / epoxy + binder) } \\
\hline & $/ \%$ & $/ \%$ & $/ \%$ \\
\hline A-RI & $54.5 \pm 1.5$ & $44.3 \pm 2.4$ & $1.0 \pm 0.4$ \\
\hline UB-RI & $51.3 \pm 1.6$ & $47.8 \pm 0.8$ & $1.1 \pm 0.3$ \\
\hline UBC-RI & $50.4 \pm 2.1$ & $48.3 \pm 1.5$ & $1.6 \pm 0.6$ \\
\hline
\end{tabular}

\section{Results and discussion}

\subsection{Processing study using coated CF fabrics}

To assess any processing differences between the as-received (A) fabric and the coated UB and UBC fabrics a preliminary processing study was conducted. Matrix digestion results in table 1 show that the UB and UBC composites had reduced volume fractions of CF and increased volume fractions of voids compared to the A composite. In addition, the thickness of the A composite produced under the vacuum-only conditions of RI was $3.18 \pm 0.03 \mathrm{~mm}$ compared to $3.57 \pm 0.08 \mathrm{~mm}$ for the composites produced with the coated CF fabrics. 
To investigate this further a compressibility study of the fabrics was carried out, by transverse compression of 4layer fabric preforms between metal anvils in an Instron 5969 testing machine, to give the pressure-thickness data presented in Figure 3. It can be seen for the binder-coated UB fabric that the uncompressed thickness of the 4-layer preform is higher and that the compressibility of this fabric is significantly lower than for the A fabric. Coating of the fabric surface has increased the rigidity of the CF tows, increasing their resistance to compression; which results in lower packing fractions of the tows [15] and can give higher levels of intra-tow voids in a composite laminate. However, the CF volume fractions of composites produced using coated fabrics can be increased by increasing the pressure and/or temperature applied during processing beyond that of the room temperature, vacuum-only pressure RI procedure used in this study; as reported from our Centre in [16] for CF fabrics coated with a thermoplastic toughener. Consequently a hybrid moulding technique, combining RI with hot-press moulding in a Dr Collin GmbH P300P/M press, was developed [16] to produce laminates with higher fibre volume fractions. The layup procedure for this HP process was almost the same as for RI except that two metal spacer plates were placed either side of the fabric stack in order to stop the moving platen of the hot press at the target thickness of the sample. The moulding cycle proceeded in the same manner as the standard RI, but once the inlet and outlet were sealed the whole assembly was placed in the hot press $\left(\right.$ at $80^{\circ} \mathrm{C}$ ) and compacted under 10 bar pressure until the spacer bars were reached and then left to cure for one hour. Following demoulding, the laminates underwent the same post-cure (8 hours at $\left.140{ }^{\circ} \mathrm{C}\right)$ in an oven.

\subsection{Fibre volume fraction}

Results from resin digestion analysis in Table 2 show all the types of laminates produced by the HP process to be now of comparable quality. The HP process generated much higher levels of compaction than RI (due to application of higher pressure), and hence laminates have increased $V_{\mathrm{f}}$. Consequently, the results reported in the remainder of this paper are for composites produced using the HP process.

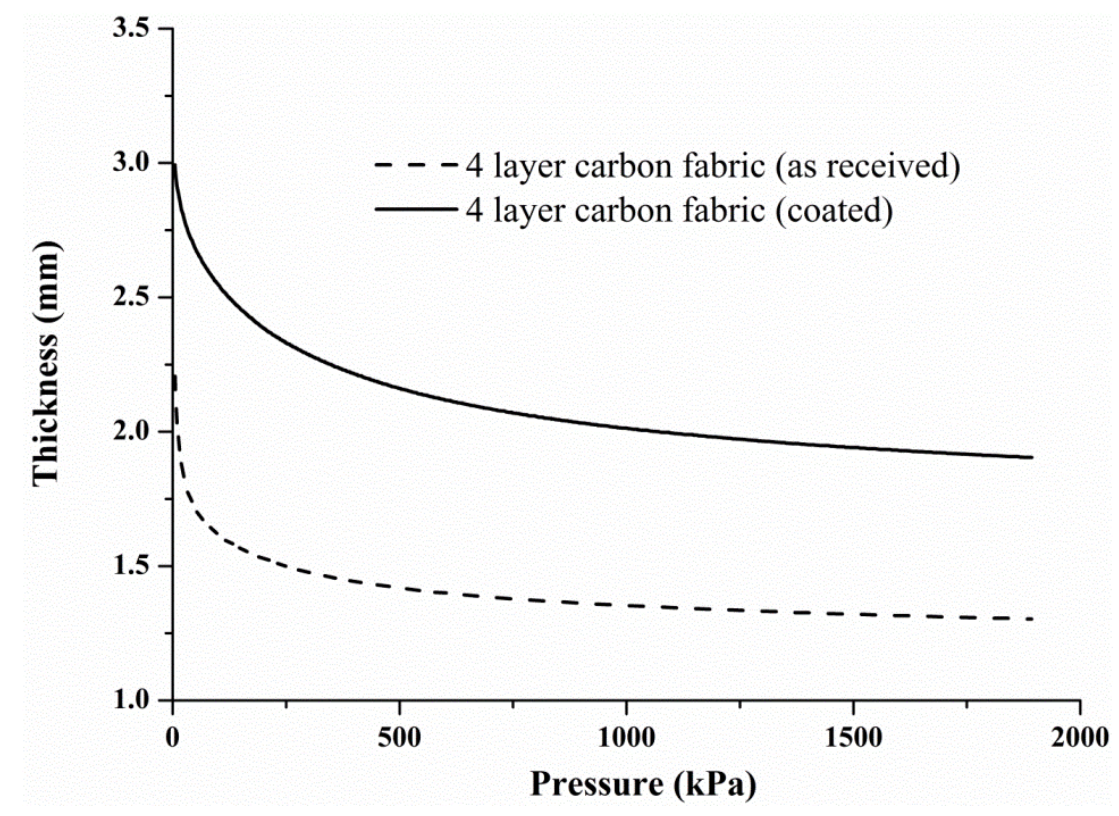

Figure 3. Pressure versus thickness curves of 4 layer preforms of the A and the coated UB fabrics. 
Table 2. Volume fraction data from matrix digestion tests for composites produced using the hybrid RI-hot press (HP) process with all five types of fabrics: as-received fabric (A); non-curable binder (UB); 1 wt.\% MWCNTs in non-curable binder (UBC); curable binder (B); 1 wt.\% MWCNTs in curable binder (BC).

\begin{tabular}{cccccc}
\hline Composites & Density & Thickness & $\begin{array}{c}\text { Reinforcement } \\
(\mathrm{CF} / \mathrm{CF}+\mathrm{CNT}) \\
\mathrm{V}_{\mathrm{r}} / \%\end{array}$ & $\begin{array}{c}\text { Matrix } \\
(\mathrm{epoxy} / \text { epoxy }+ \\
\text { binder }) \mathrm{V}_{\mathrm{m}} / \%\end{array}$ & $\begin{array}{c}\text { Voids } \\
\mathrm{V}_{\mathrm{v}} / \%\end{array}$ \\
\hline $\mathrm{A}$ & $1.498 \pm 0.003$ & $3.18 \pm 0.03$ & $54.9 \pm 2.3$ & $44.6 \pm 3.3$ & $0.8 \pm 0.4$ \\
$\mathrm{UB}$ & $1.503 \pm 0.010$ & $3.18 \pm 0.04$ & $55.5 \pm 0.2$ & $44.1 \pm 0.8$ & $0.4 \pm 0.1$ \\
$\mathrm{UBC}$ & $1.501 \pm 0.007$ & $3.17 \pm 0.11$ & $55.1 \pm 1.7$ & $43.9 \pm 0.3$ & $0.8 \pm 0.5$ \\
$\mathrm{~B}$ & $1.501 \pm 0.008$ & $3.19 \pm 0.08$ & $54.3 \pm 0.3$ & $44.1 \pm 0.5$ & $0.6 \pm 0.3$ \\
$\mathrm{BC}$ & $1.498 \pm 0.007$ & $3.21 \pm 0.03$ & $54.6 \pm 0.4$ & $44.8 \pm 0.9$ & $0.5 \pm 0.3$ \\
\hline
\end{tabular}

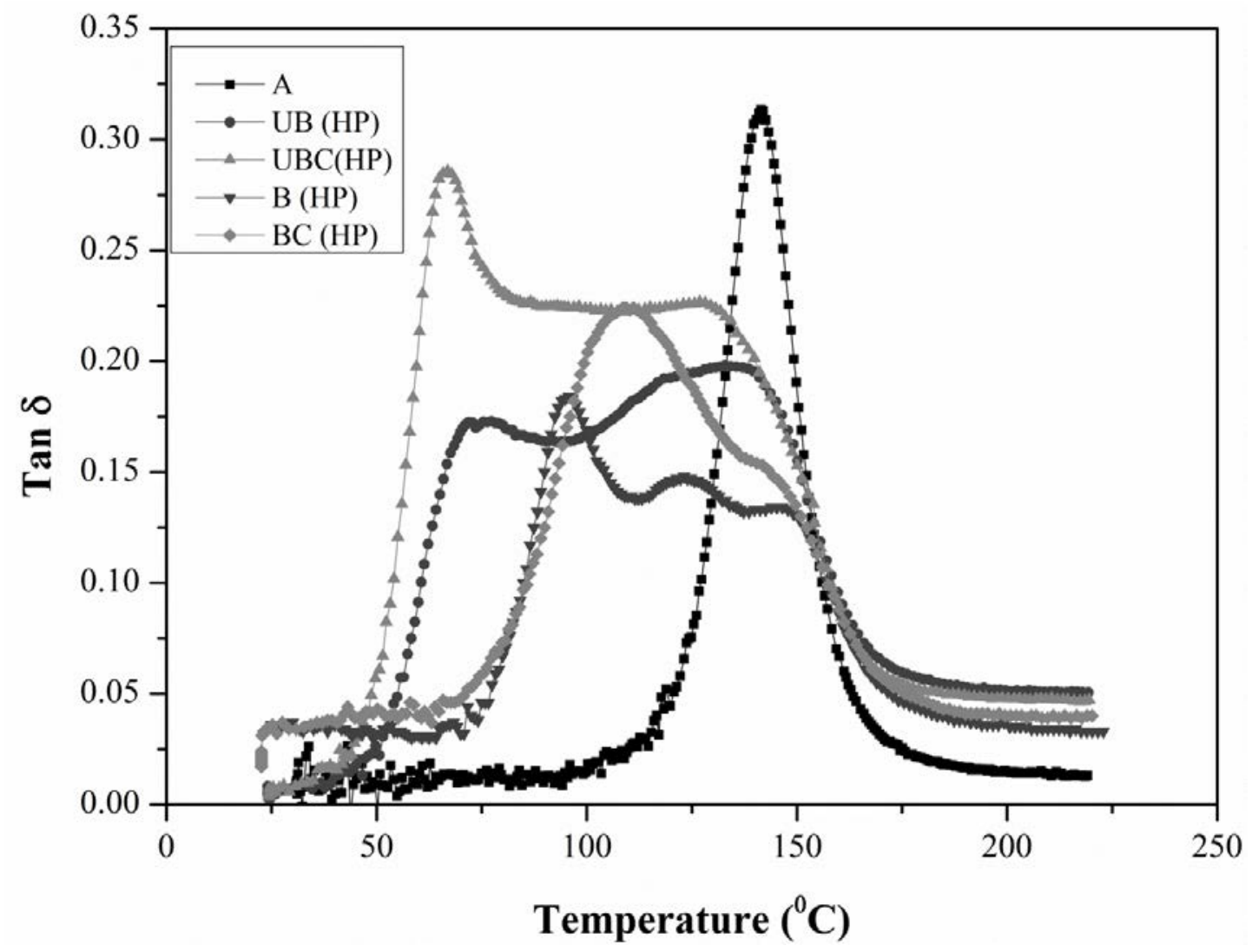

Figure 4. Typical curves of $\tan \delta$ as a function of temperature for composites produced using as-received fabric (A) and four types of coated fabrics: non-curable binder (UB); 1 wt.\% MWCNTs in non-curable binder (UBC); curable binder (B); 1 wt.\% MWCNTs in curable binder (BC).

\subsection{DMTA}

Typical DMTA data for the composites are shown in figures 4 and 5 and average derived properties are given in table 3. The damping data in figure 4 and table 3 show that composite A exhibits only a single $\alpha$-peak in $\tan \delta$ at $\approx 140{ }^{\circ} \mathrm{C}$, assigned to the $\mathrm{T}_{\mathrm{g}}$ of the matrix epoxy, whereas composites containing uncured binder (UB, UBC) also 
exhibit a lower temperature $\gamma$ - peak at $\approx 67 \pm 2{ }^{\circ} \mathrm{C}$ assigned to the binder, as well as a reduced temperature $\alpha$-peak at $\approx 132 \pm 2{ }^{\circ} \mathrm{C}$. This reduction in the $\mathrm{T}_{\mathrm{g}}$ of the matrix epoxy may be ascribed to a stoichiometric imbalance resulting from loss of hardener by molecular diffusion across the interface into the binder epoxy, as reported for epoxy sizes on CF by Drzal et al [17]. Diffusion may occur in the period prior to matrix gelation during curing at $80^{\circ} \mathrm{C}$; a period which will be at least the $40 \pm 5$ min quoted by the resin manufacturer for the balanced stoichiometry system. Alternatively, the $\tan \delta$ curve for the UB composite shows that a significant degree of phase mixing has occurred between the matrix epoxy resin and the uncured binder, as indicated by the shift to a lower temperature of the $\alpha$-peak accompanied by a reduction in peak $\tan \delta$ value from 0.32 to 0.2 and a significant broadening of the transition peak. These changes result in the $\gamma$ - peak merging with the $\alpha$-peak, with the small shoulder in the data at $\approx 120^{\circ} \mathrm{C}$ indicative of a $\beta$-transition due to the formation of a third, mixed phase. It may be envisioned that this multiphase system forms due to reaction-induced phase separation (RIPS) [18] as the composite cures at $80^{\circ} \mathrm{C}$. Initially the binder, upon reaching its melting point, starts to phase mix with the matrix resin system in the interlaminar regions of the laminate to form a homogeneous phase which, as curing proceeds and molar mass increases, then undergoes RIPS to form two impure phases dominated by either the matrix epoxy system ( $\alpha$-phase) or by the lower $\mathrm{T}_{\mathrm{g}}\left(40^{\circ} \mathrm{C}\right)$ binder epoxy ( $\gamma$-phase) and a third mixed $\beta$-phase, as RIPS is interrupted by the gelation of the matrix epoxy system. The addition of $1 \mathrm{wt} . \%$ of MWCNTs to the binder in the UBC composite changes these effects to a degree. Thus, compared to UB, the low temperature damping is increased significantly; with the $\gamma$-peak $\tan \delta$ value increasing from 0.18 to 0.28 accompanied by a significant narrowing of the transition peak, although the temperature at the peak remains within the range $67 \pm 2$ ${ }^{\circ} \mathrm{C}$. For the $\gamma$ - peak, the peak tan $\delta$ value increases from 0.2 to 0.25 although again the temperature at the peak remains within the range $132 \pm 2{ }^{\circ} \mathrm{C}$. The biggest change, however, is the merging of the $\beta$ - and $\alpha$-peaks to give a plateau in the damping data which extends from approximately 75 up to $130{ }^{\circ} \mathrm{C}$. The dispersion of NC7000 MWCNTs into the binder resulted in a significant increase in viscosity, as we have found previously for other epoxy systems [11], which will potentially hinder both the initial phase mixing of the binder with the matrix epoxy system and any subsequent demixing of any homogeneous phase due to RIPS, whilst providing additional damping mechanisms due to binder-MWCNT interactions. Very significant changes in damping behaviour occurred upon curing of the binder, as shown by the data for the B and BC composites in figure 4 and table 3. Compared to the UB composite, the B composite shows increases in the peak temperatures for both the $\alpha\left(+6{ }^{\circ} \mathrm{C}\right)$ and the $\gamma\left(+24^{\circ} \mathrm{C}\right)$ transitions; the latter transition now exhibits a well-defined peak whereas the former is reduced to little more than a shoulder on a more distinct mixed-phase $\beta$ - transition which retains a peak temperature of $\approx 120{ }^{\circ} \mathrm{C}$. Thus, curing of the binder has produced a $\gamma$-phase with a much higher $\mathrm{T}_{\mathrm{g}}$ of $94{ }^{\circ} \mathrm{C}$ (as it is now crosslinked) which correlates well with the value of $90{ }^{\circ} \mathrm{C}$ quoted previously for this system cured with the same level of dicy [12], as well as a more distinct 3 phase structure in the matrix. In contrast, the addition of 1 wt.\% MWCNTs to the cured binder in the BC composite results in a single, broad $\beta$-transition damping peak between $\approx 70$ to $\approx 170{ }^{\circ} \mathrm{C}$, with a peak temperature of $\approx 111^{\circ} \mathrm{C}$ and an $\alpha$-transition shoulder at $\approx 151{ }^{\circ} \mathrm{C}$. This change is indicative of a high degree of phase mixing, and it appears that the combination of a reactive binder with addition of MWCNTs has inhibited RIPS significantly. It may be envisaged that despite the increase in viscosity due to incorporating MWCNTs there was no significant inhibition of the initial phase mixing of the binder with the matrix epoxy system during the initial stage of the cure cycle ( $80{ }^{\circ} \mathrm{C}$ for 1 hour) indicating that sufficient time was still available for dissolution of the binder resin. RIPS is initiated in these systems by the increase in molar mass during network-forming polymerisation, and the degrees of residual phase mixing that occurred in the systems with unfilled binders (UB/B) indicate that insufficient time is available for RIPS to reach 
a high degree of completion. In the BC composite, therefore, the presence of the MWCNTs in the homogeneous phase providing resin-nanotube interactions and the resultant increase in viscosity will further inhibit RIPS.

Table 3. DMTA data for composites produced using as-received fabric (A) and four types of coated fabrics: non-curable binder (UB); 1 wt.\% MWCNTs in non-curable binder (UBC); curable binder (B); 1 wt.\% MWCNTs in curable binder (BC). The symbol (s) indicates a shoulder on a larger peak.

\begin{tabular}{|c|c|c|c|c|c|c|}
\hline \multirow{3}{*}{ Composite } & & & & \multirow{3}{*}{$\begin{array}{c}\gamma-\text { peak } \\
\text { Binder } \mathrm{T}_{\mathrm{g}} \\
\quad /{ }^{\circ} \mathrm{C}\end{array}$} & \multirow{3}{*}{$\begin{array}{c}\beta-\text { peak } \\
\text { Mixed Phase } \mathrm{T}_{\mathrm{g}} \\
{ }^{\circ} \mathrm{C}\end{array}$} & \multirow{3}{*}{$\begin{array}{c}\alpha-\text { peak } \\
\text { Matrix Epoxy } \mathrm{T}_{\mathrm{g}} \\
{ }^{\circ} \mathrm{C}\end{array}$} \\
\hline & \multicolumn{3}{|c|}{$\begin{array}{l}\text { Storage modulus E' } \\
\qquad / \mathrm{GPa}\end{array}$} & & & \\
\hline & $25^{\circ} \mathrm{C}$ & $50^{\circ} \mathrm{C}$ & $100{ }^{\circ} \mathrm{C}$ & & & \\
\hline A & $54 \pm 4.5$ & $52 \pm 2.1$ & $50 \pm 3.3$ & - & - & $140 \pm 0.8$ \\
\hline UB & $20 \pm 1.1$ & $19 \pm 0.9$ & $2 \pm 0.3$ & $69 \pm 0.5$ & $121 \pm 0.2(\mathrm{~s})$ & $134 \pm 1.2$ \\
\hline UBC & $21 \pm 0.7$ & $19 \pm 0.8$ & $4 \pm 0.1$ & $66 \pm 1.1$ & - & $130 \pm 1.0$ \\
\hline B & $28 \pm 4.2$ & $27 \pm 4.1$ & $11 \pm 1.9$ & $94 \pm 0.3$ & $123 \pm 0.8$ & $146 \pm 0.4$ \\
\hline BC & $34 \pm 2.4$ & $33 \pm 2.5$ & $14 \pm 1.2$ & - & $111 \pm 1.5$ & $151 \pm 0.9(\mathrm{~s})$ \\
\hline
\end{tabular}

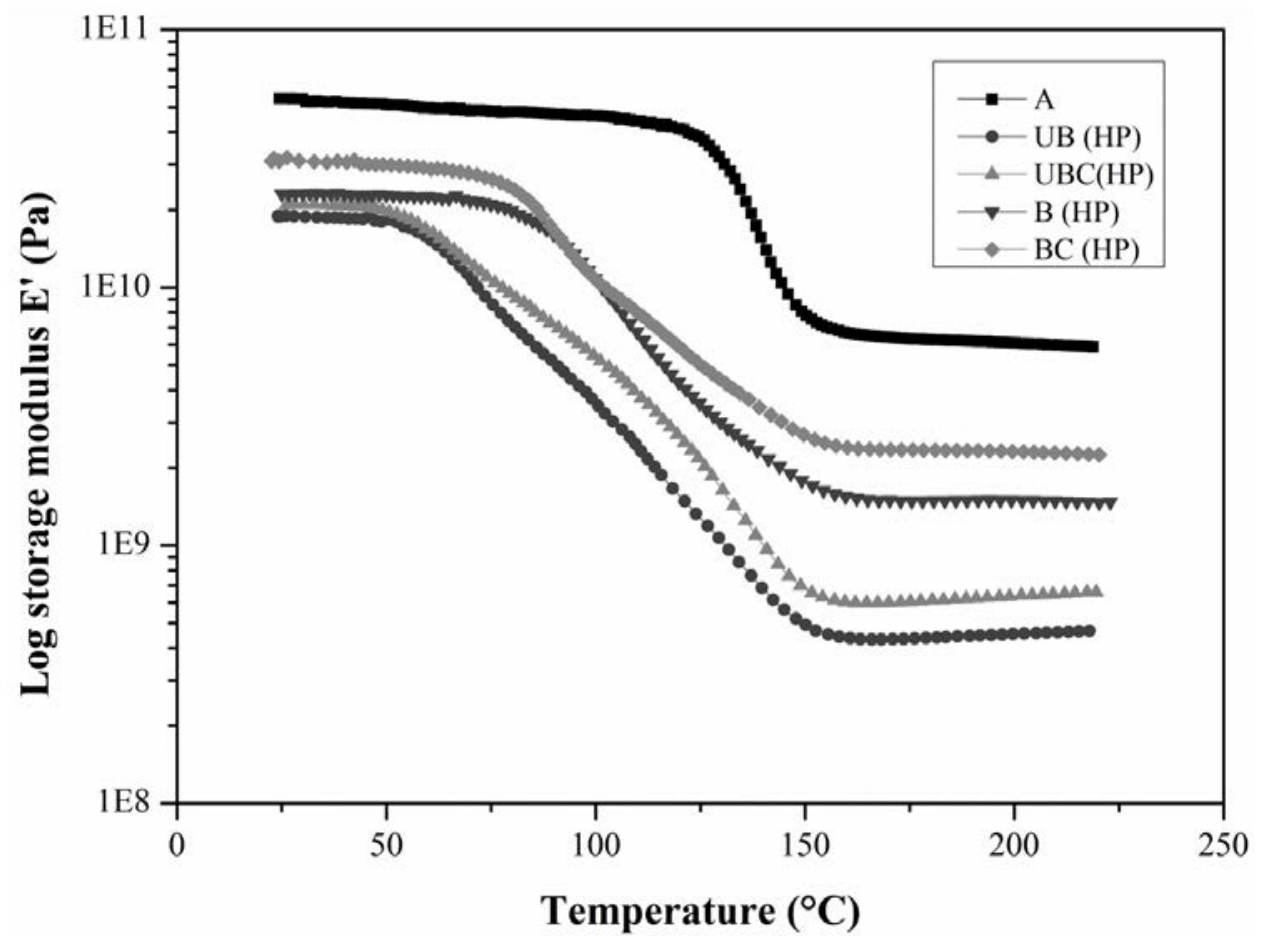

Figure 5. Typical curves of storage modulus as a function of temperature for composites produced using asreceived fabric (A) and four types of coated fabrics: non-curable binder (UB); 1 wt.\% MWCNTs in non-curable binder (UBC); curable binder (B); 1 wt.\% MWCNTs in curable binder (BC).

The data in Figure 5 and table 3 show (compared to composite A) that the changes in the structure of the matrix resulting from the addition of binder in the UB composite significantly reduce the values of storage modulus ( $\mathrm{E}^{\prime}$ ) across the full experimental temperature range. In addition, the softening of the binder as it reaches its $T_{\mathrm{g}}$ causes the onset of the drop in $\mathrm{E}^{\prime}$ at the start of the transition (sometimes termed the engineering $\mathrm{T}_{\mathrm{g}}$ ) to fall from $\approx 125$ to $\approx 95{ }^{\circ} \mathrm{C}$. The addition of MWCNTs into the uncured binder of the UBC composite addresses this problem but 
only to a small degree. Crosslinking the binder (composite B) addresses the drop in $\mathrm{E}^{\prime}$ to a much greater degree, and the addition of MWCNTs to the cured binder (composite BC) resulted in the highest values of $\mathrm{E}^{\prime}$ of the coated-fabric composites; however, there is still a marked reduction compared to composite A across the full experimental temperature range. Increasing the addition level of MWCNTs to $\geq 2 \mathrm{wt} . \%$ may improve the situation in regard to $E^{\prime}$ but, as discussed previously, was found to cause problems with fabric coating although this is still a route to be explored further. In addition, other approaches such as treating the MWCNTs to improve their interfacial adhesion with the binder, curing the binder before composite processing and the use of higher $\mathrm{T}_{\mathrm{g}}$ epoxy binders to coat the fabrics are currently being explored.

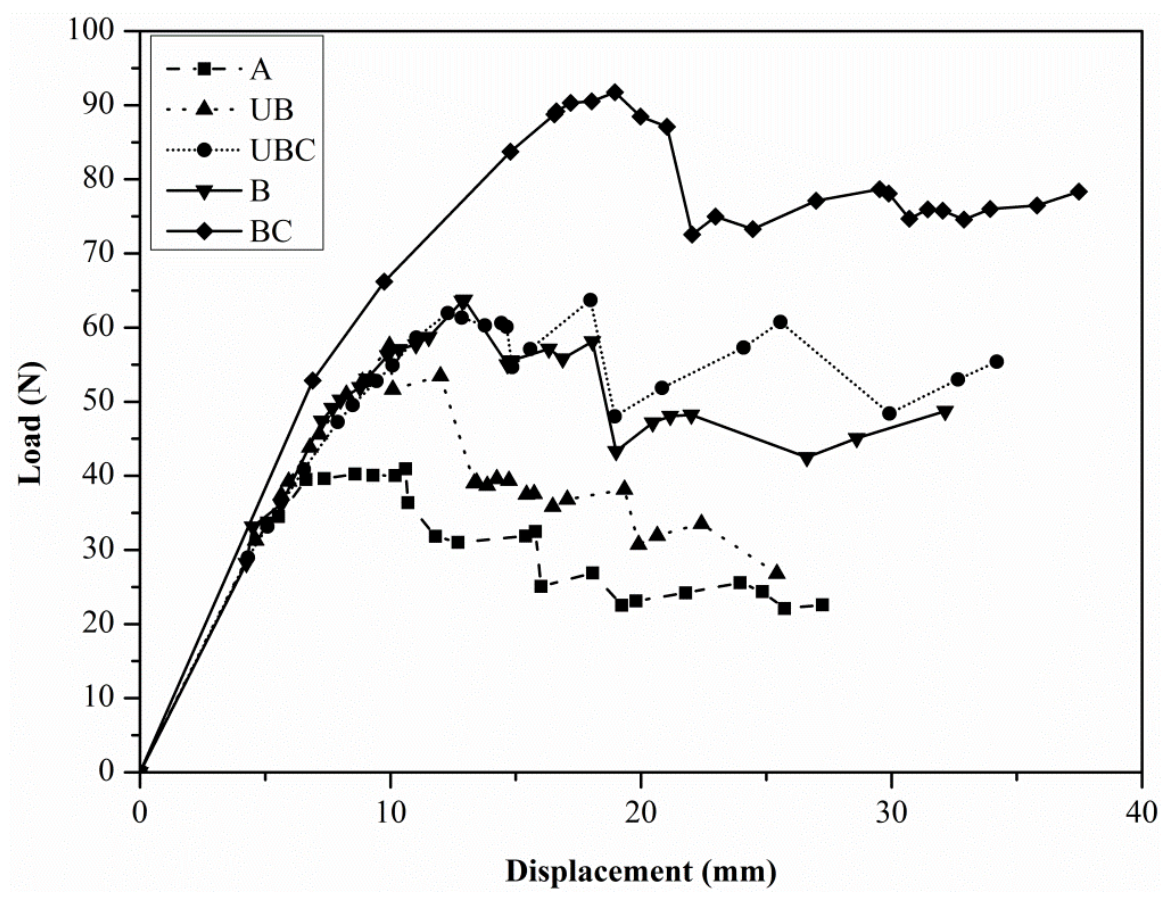

Figure 6. Typical DCB load-displacement curves for composites produced using as-received fabric (A) and four types of coated fabrics: non-curable binder (UB); 1 wt.\% MWCNTs in non-curable binder (UBC); curable binder (B); 1 wt.\% MWCNTs in curable binder (BC).

\subsection{Mode I ILFT}

The typical load-extension curves from the DCB tests in figure 6 all show an initial region with a steep but stable rise in load followed by a region of unstable decline as the crack propagates, although the load-displacement curves of the coated fabric composites are significantly less stable than for composite A. For the coated fabric composites, crack initiation was observed to occur at higher displacements and at much higher maximum loads which increase in the order $\mathrm{A}<\mathrm{UB}<\mathrm{UBC} \approx \mathrm{B}<<\mathrm{BC}$, an order which continues in the load levels in the region of unstable decline. The unstable behaviour for composite A results solely from the 5-harness satin weave fabric used which generates crack deflection, branching and bowing caused by the transverse fibre bundles of the weave as described by Kuwata and Hogg [19]. Whereas for the UB and B composites the addition of binder both delays crack initiation and produces more unstable crack propagation through the multiphase matrix formed by RIPS, in which the secondary-phase particles can generate one or more of a number of potential additional toughening mechanisms; such as deflection of the crack, deformation of the secondary-phase particles or microcracking [20]. Similarly, the addition of MWCNTs to the UBC and BC composites introduces additional toughening mechanisms such as tube pull-out and fracture, both of which can contribute significantly to increasing fracture energy [21]. 
Table 4. Average values for mode I ILFT G $\mathrm{G}_{\mathrm{IC}}$ for composites produced using as-received fabric (A) and four types of coated fabrics: non-curable binder (UB); 1 wt.\% MWCNTs in non-curable binder (UBC); curable binder (B); 1 wt.\% MWCNTs in curable binder (BC).

\begin{tabular}{cccccc}
\hline Composite & $\mathrm{G}_{\text {IC-Max }}$ & $\mathrm{G}_{\text {IC-Vis }}$ & $\mathrm{G}_{\text {IC-NL }}$ & $\mathrm{G}_{\text {IC-Prop }}$ & $\begin{array}{c}\text { \% increase in } \\
\mathrm{G}_{\text {IC-Prop }} \\
\text { relative to A }\end{array}$ \\
\hline A & $/ \mathrm{kJm}^{-2}$ & $\mathrm{kJm}^{-2}$ & $\mathrm{kJm}^{-2}$ & $\mathrm{kJm}^{-2}$ & - \\
$\mathrm{UB}$ & $0.52 \pm 0.07$ & $0.47 \pm 0.02$ & $0.42 \pm 0.02$ & $0.47 \pm 0.04$ & - \\
$\mathrm{UBC}$ & $1.22 \pm 0.20$ & $1.18 \pm 0.14$ & $0.92 \pm 0.09$ & $0.99 \pm 0.12$ & $110 \pm 25$ \\
B & $0.92 \pm 0.02$ & $0.79 \pm 0.04$ & $0.58 \pm 0.03$ & $0.88 \pm 0.04$ & $87 \pm 8$ \\
BC & $1.46 \pm 0.13$ & $1.27 \pm 0.03$ & $1.08 \pm 0.09$ & $1.54 \pm 0.06$ & $234 \pm 13$ \\
\hline
\end{tabular}

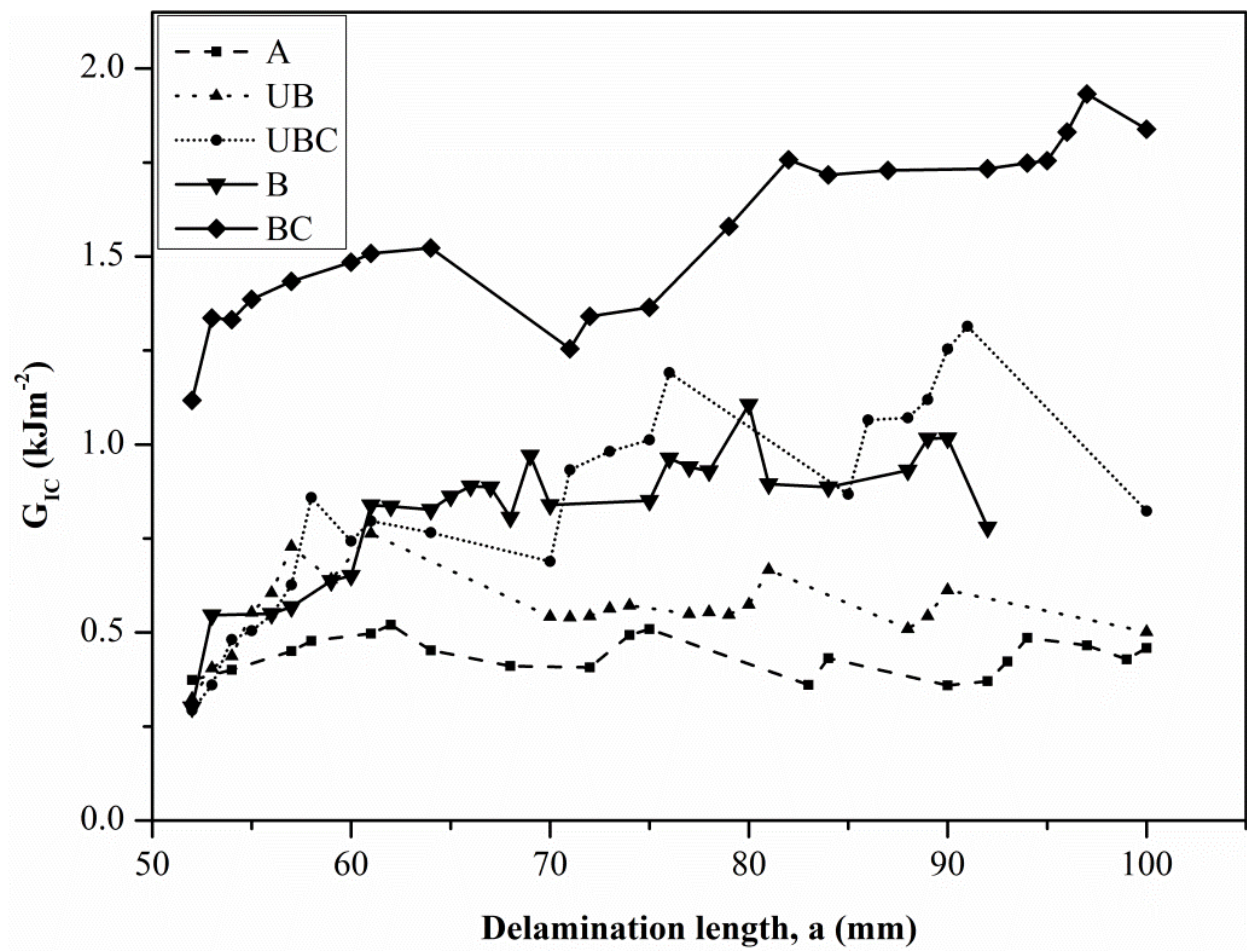

Figure 7. Typical R-curves from mode 1 DCB tests for composites produced using as-received fabric (A) and four types of coated fabrics: non-curable binder (UB); 1 wt.\% MWCNTs in non-curable binder (UBC); curable binder (B); 1 wt.\% MWCNTs in curable binder (BC).

In comparison to the use of uncoated fabric (composite $A$ ) the derived values of $G_{I}$ in the R-curves in figure 7 and table 4 show increased values for the UB composite on addition of uncured binder of the order of $40 \pm 10 \%$. However, it is the addition of MWCNTs that has the dominant effect which, relative to the UB composite, results in increases in $G_{I}$ values for the UBC composite of $\approx 64 \%$ for the initiation values and $57 \%$ for propagation (which is $+110 \%$ compared to composite A). Crosslinking the binder (that is, composite B vs. UB) generally resulted in relatively small increases in initiation $\mathrm{G}_{\mathrm{I}}$ values $\left(\leq 13 \%\right.$ except for $\mathrm{G}_{\text {IC-Max }}$ which increased by 38\%) 
but the increase in $\mathrm{G}_{\text {IC-Prop }}$ is 40\%. However, once again it is the addition of MWCNTs to the cured binder (composite BC) that has resulted in the biggest increases as shown in Table 4; the increase of 56\% compared to composite UBC (with uncured binder) may be indicative of an increase in interfacial shear strength upon crosslinking the binder as, assuming all MWCNTs parameters are the same, this is the only matrix parameter that significantly affects the energy required to pull-out a nanotube [21].
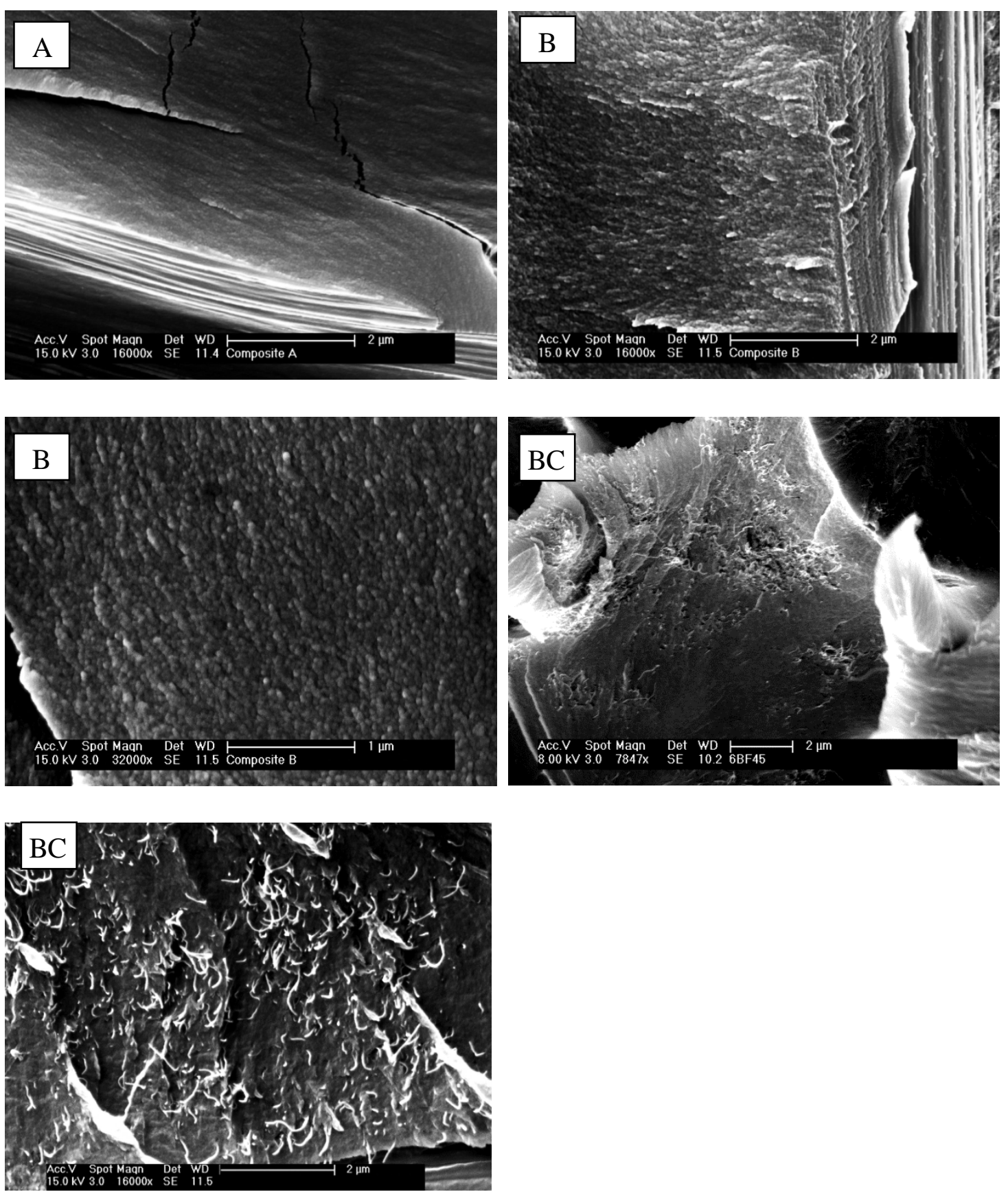

Figure 8. Typical SEM micrographs of matrix fracture surfaces from Mode I DCB specimens for composites produced using: i) as-received fabric (A), showing a relatively smooth fracture surface and two types of coated fabrics; ii) curable binder (B), at two magnifications, showing rough fracture surfaces and evidence of submicron secondary phase inclusions in this multiphase matrix; iii) $1 \mathrm{wt}$ \% MWCNTs in curable binder (BC), at two magnifications, showing typical $\mu \mathrm{m}$-scale agglomerates of MWCNTs and evidence of nanotubes that have fractured whilst being pulled out of the matrix. 
The changes in matrix morphology indicated by DMTA upon coating the CF reinforcement with binder or with binder containing MWCNTs were reflected in the matrix fracture surfaces following Mode I DCB testing. The SEM micrographs in figure 8 show a progression from the relatively smooth fracture surface typical of an unmodified epoxy resin (composite A) to the much rougher surface generated by a multiphase matrix (composite B) containing sub-micron secondary phase inclusions and finally to a fracture surface showing extensive evidence of pull-out and fracture of MWCNTs (composite BC). The matrix morphology of the BC composite observed from SEM images, such as those shown in figure 8, is of an epoxy matrix containing dispersed MWCNTs, although the distribution of these dispersed nanotubes is not homogeneous, and the MWCNTs predominantly reside in $\mu \mathrm{m}$-scale agglomerates. CVD-grown MWCNTs such as NC7000 are highly entangled, and will retain a degree of entanglement even after intensive shear mixing. As the mixtures of MWCNTs in epoxy binder appeared well dispersed and stable at room temperature, it is possible therefore that some of the agglomerates formed due to reagglomeration of the MWCNTs during the high temperature curing cycle of the resin system, as observed by Ma et al for epoxy-MWCNT systems [4]. The viscosity of the epoxy resin system used in this study has been measured in our laboratory to drop by over an order of magnitude during the period prior to matrix gelation on curing at $80^{\circ} \mathrm{C}$ which will promote reagglomeration of the MWCNTs. Despite their agglomeration, the SEM images show the MWCNTs to exhibit the toughening mechanisms described by Hsieh et al [21]; in which the nanotubes first debond from the matrix then pull-out. Thus, energy is absorbed due to friction between a nanotube and the matrix as pull-out occurs up to fracture of the nanotube (as the nanotubes are long, and not straight, they will tend to rupture rather than pull out completely). Hsieh at al [21] also modelled the energy absorbtion due to the toughening mechanisms exhibited by MWCNTs in an epoxy matrix. Addition of 0.1 or 0.2 wt.\% of MWCNTs resulted in pull-out of $100 \%$ of the nanotubes, whereas only $62 \%$ were observed to pull-out on addition of 0.5 wt.\% due to increased nanotube agglomeration. Despite this, their measured $\mathrm{G}_{\text {IC }}$ increased by $60 \%$ compared to the unfilled matrix; for which modelling showed the major contributors to the increase energy absorbtion to be nanotube debonding and pull-out (responsible for $\approx 23 \%$ and $\approx 37 \%$ of the $60 \%$ increase, respectively). In the present study, despite the apparent higher addition level in the binder (note however that $1 \mathrm{wt} . \%$ in the binder is only $\approx 0.25 \mathrm{wt} . \%$ in the full matrix including the LY564/2954 epoxy resin system) and any reagglomeration of the MWCNTs, significant evidence of nanotube pull-out and fracture was observed and increases in $\mathrm{G}_{\text {IC-Prop }}$ of $\approx 60 \%$ and $\approx 75 \%$ were measured upon addition of MWCNTs to the uncured and cured binders in composites UBC and BC, respectively.

There are several reports in the literature of improved mode I ILFT of multi-scale composites containing MWCNTs. For example, Kepple et al [8] used CVD to grow MWCNTs on the surface of CF and reported an increase of $50 \%$ in $\mathrm{G}_{\mathrm{IC}}$ for an epoxy matrix composite. However, the growth procedure was relatively lengthy and complicated and the high temperatures required for CVD $\left(\approx 800^{\circ} \mathrm{C}\right)$ may damage CFs. Zhang et al [9] applied 0.047 wt.\% of MWCNTs to a CF pre-preg from a methanol dispersion via spray coating and measured an increase in mode I ILFT of $50 \%$. Although a relatively quick process, residual solvent may affect processing of the prepreg and it was only possible to add a relatively small wt.\% of MWCNTs into the composite compared to the $\approx 0.25 \mathrm{wt} . \%$ introduced during the current study. . Composites produced by Herceg et al [10] using CF pre-pregs with levels of MWCNTs of up to 6.1 vol.\% showed increases of $24 \%$ for mode I ILFT, ascribed to MWCNTs increasing both the strength of the CF-matrix interface and the toughness of the matrix. From fractography, they concluded that in the composites with MWCNTs cracks propagated both along the fibrematrix interface and through the matrix within the interlaminar region, which is similar to the crack propagation observed for composites B and BC in the current study. Orientation of MWCNTs within a composite also plays 
an important role as shown by Wicks et al [2]. Epoxy matrix composites were prepared using alumina fibre cloth reinforcement with aligned MWCNTs grown on its surface using CVD. Composites containing 1-2 vol.\% MWCNTs had mode I ILFT increased by 67\%; ascribed to nanotube pull-out, as observed in their SEM micrographs. As discussed, MWCNTs can be introduced to fibre reinforced composites using a range of different approaches and each has its advantages and disadvantages. The approach used in this research is a relatively simple process to introduce a relatively high wt.\% of MWCNTs and one which does not require solvents or very high temperature treatment of the CF.

\subsection{Mode II ILFT}

The typical R curves from 4ENF tests shown in figure 9 all show unstable crack propagation, similar to the mode I DCB tests. In comparison to composite A, the derived values of $\mathrm{G}_{\text {IIC-Prop }}$ in table 5 show an increase of only $18 \pm 14 \%$ for the UB composite on addition of uncured binder due to the formation of a multiphase matrix by RIPS (as indicated by the DMTA damping data) and the additional toughening mechanisms that such a morphology provides. The addition of MWCNTs, which introduce additional toughening mechanisms such as

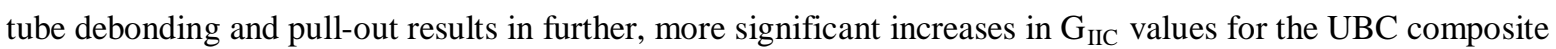
of $\approx 28 \%$ for the initiation values and $33 \%$ for propagation compared to the UB composite. However, it is the addition of the curable binder that has the most significant effect on the $\mathrm{G}_{\text {IIC-Prop }}$ values, which increase by $\approx 20 \%$ for the B composite compared to the UB composite (which equates to $+40 \%$ compared to composite A) and by $\approx 30 \%$ for the $\mathrm{BC}$ composite compared to the UBC composite, (which equates to $+106 \%$ compared to composite A). These increases in fracture energy result from changes in the morphology of the interlaminar region upon curing of the binder. The DMTA damping data showed curing of the binder produced a binderdominated $\gamma$-phase with a much higher softening temperature (rising by $25^{\circ} \mathrm{C}$ as it is now crosslinked) as well as a more distinct 3-phase structure, which will enhance the toughening effects of this multiphase matrix.

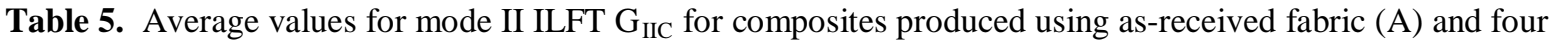
types of coated fabrics: non-curable binder (UB); 1 wt.\% MWCNTs in non-curable binder (UBC); curable binder (B); 1 wt.\% MWCNTs in curable binder (BC).

\begin{tabular}{|c|c|c|c|c|c|}
\hline Composite & $\begin{array}{c}\mathrm{G}_{\text {IIC-MAX }} \\
\mathrm{kJm}^{-2}\end{array}$ & $\begin{array}{l}\mathrm{G}_{\text {IIC-VIS }} \\
\mathrm{kJm}^{-2}\end{array}$ & $\begin{array}{l}\mathrm{G}_{\mathrm{IIC}-\mathrm{NL}} \\
/ \mathrm{kJm}^{-2}\end{array}$ & $\begin{array}{c}\mathrm{G}_{\text {IIC-Prop }} \\
\mathrm{kJm}^{-2}\end{array}$ & $\begin{array}{l}\text { \% increase in } \\
\text { G } \text { GIC-Prop } \\
\text { relative to A }\end{array}$ \\
\hline A & $1.49 \pm 0.21$ & $1.20 \pm 0.09$ & $1.09 \pm 0.03$ & $1.38 \pm 0.22$ & - \\
\hline UB & $1.84 \pm 0.06$ & $1.05 \pm 0.17$ & $0.96 \pm 0.21$ & $1.74 \pm 0.31$ & $18 \pm 14$ \\
\hline UBC & $1.40 \pm 0.27$ & $1.35 \pm 0.25$ & $1.23 \pm 0.05$ & $2.33 \pm 0.32$ & $57 \pm 21$ \\
\hline B & $2.13 \pm 0.16$ & $1.41 \pm 0.21$ & $1.13 \pm 0.17$ & $2.07 \pm 0.15$ & $40 \pm 10$ \\
\hline $\mathrm{BC}$ & $2.53 \pm 0.07$ & $2.27 \pm 0.11$ & $1.57 \pm 0.02$ & $3.04 \pm 0.02$ & $106 \pm 2$ \\
\hline
\end{tabular}




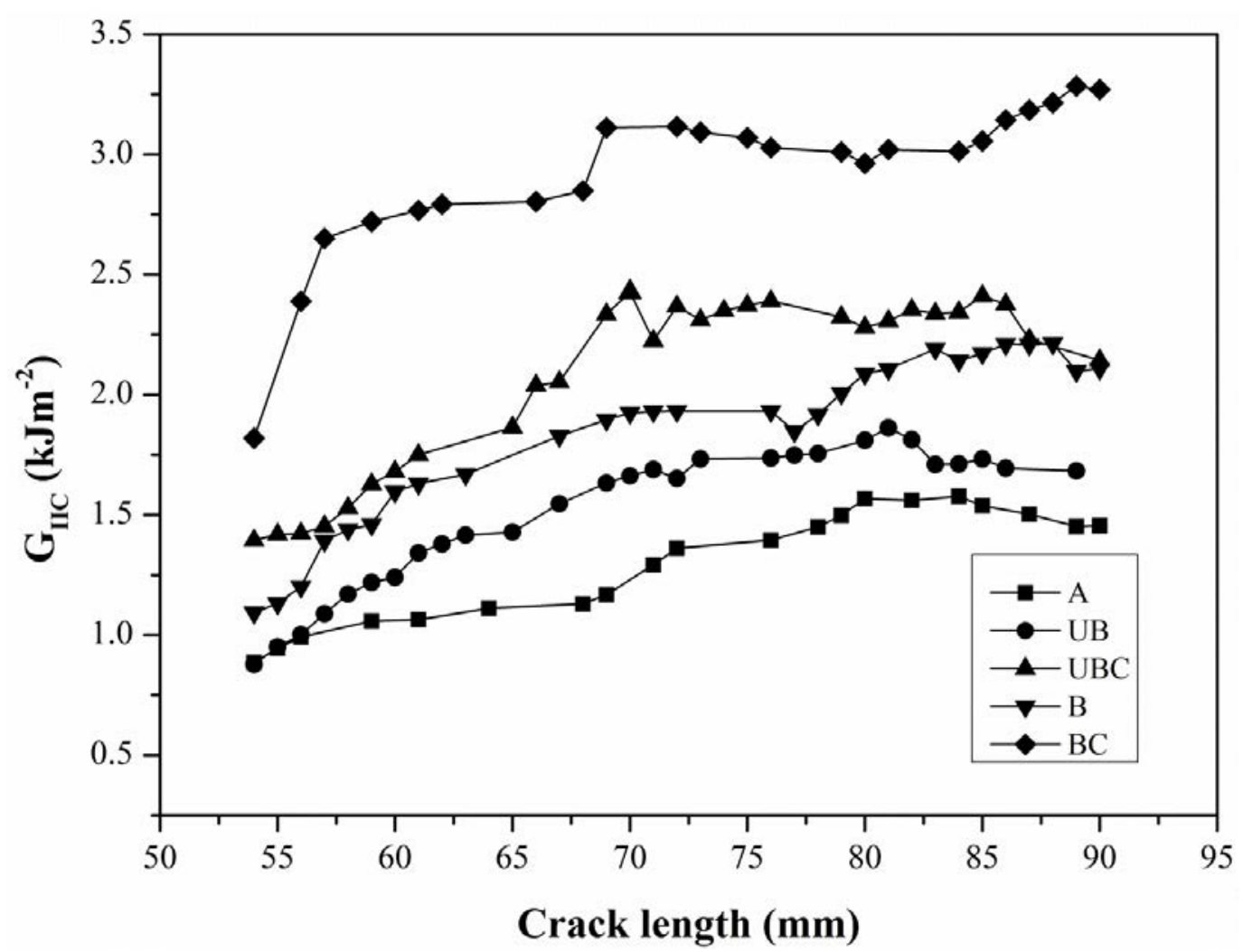

Figure 9. Typical R-curves from mode II 4ENF tests for composites produced using as-received fabric (A) and four types of coated fabrics: non-curable binder (UB); 1 wt.\% MWCNTs in non-curable binder (UBC); curable binder (B); 1 wt.\% MWCNTs in curable binder (BC).

Figure 10 shows SEM micrographs of mode II fracture surfaces of composites A, B and BC. For composite A, the micrographs show almost entirely interfacial failure where exposed fibres are free of matrix and the fracture surface of the matrix is relatively smooth. In contrast, for composite B the micrographs show fibres that are partcovered with matrix and the fracture surface of the matrix is rougher and shows evidence of sub-micron secondary-phase particles, which is indicative of both increased interfacial bonding and of increased matrix toughness due to the formation of a multiphase matrix. For the BC composite, addition of MWCNTs enhances the fracture resistance of the matrix by introducing additional toughening mechanisms such as tube pull-out and fracture [21]. This is confirmed by the micrographs which show pulled-out sections of MWCNTs on the fracture surfaces. It can also be seen that the MWCNTs reside predominantly in $\mu \mathrm{m}$-scale agglomerates as discussed previously. The presence of MWCNTs and their agglomerates throughout the binder-toughened matrix create abrupt stiffness variations and introduce local disturbances in the stress distribution, which have been shown to result in crack deflection in epoxy-MWCNT nanocomposites [21, 11]. This inhibits propagation through the matrix as a crack must pass either through or around areas with different stiffness which results in an increase in energy absorbance. 

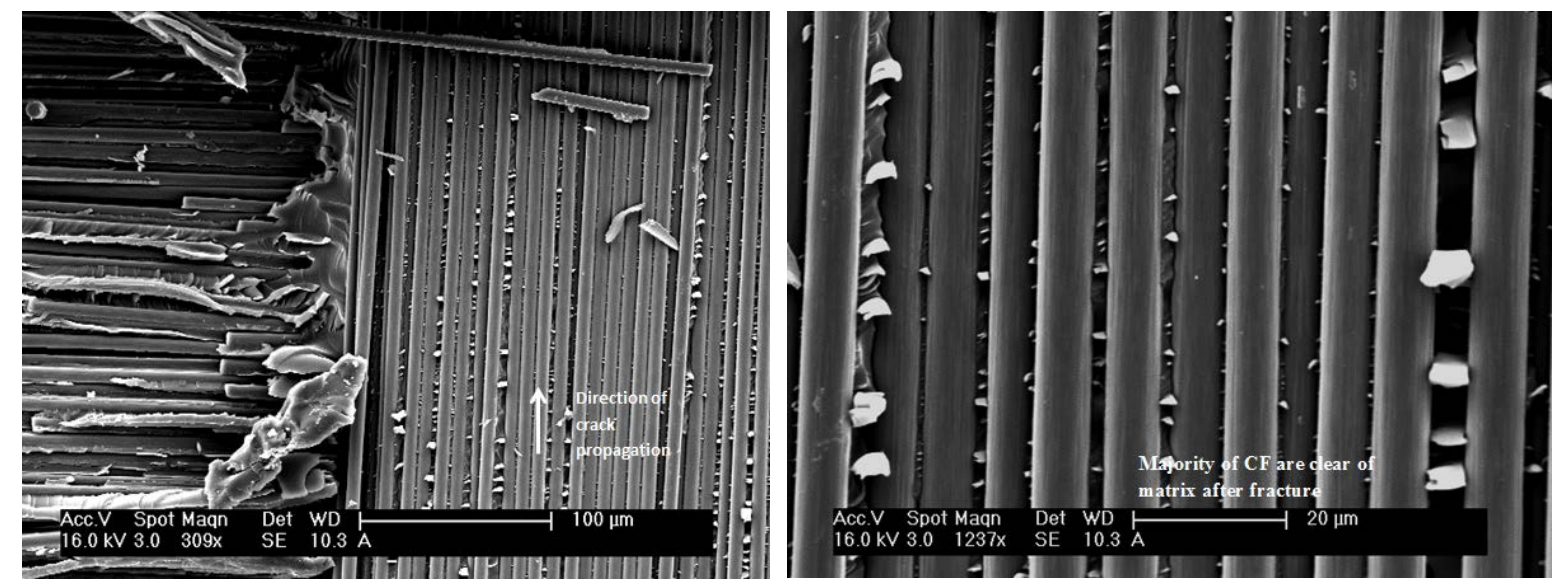

Composite A
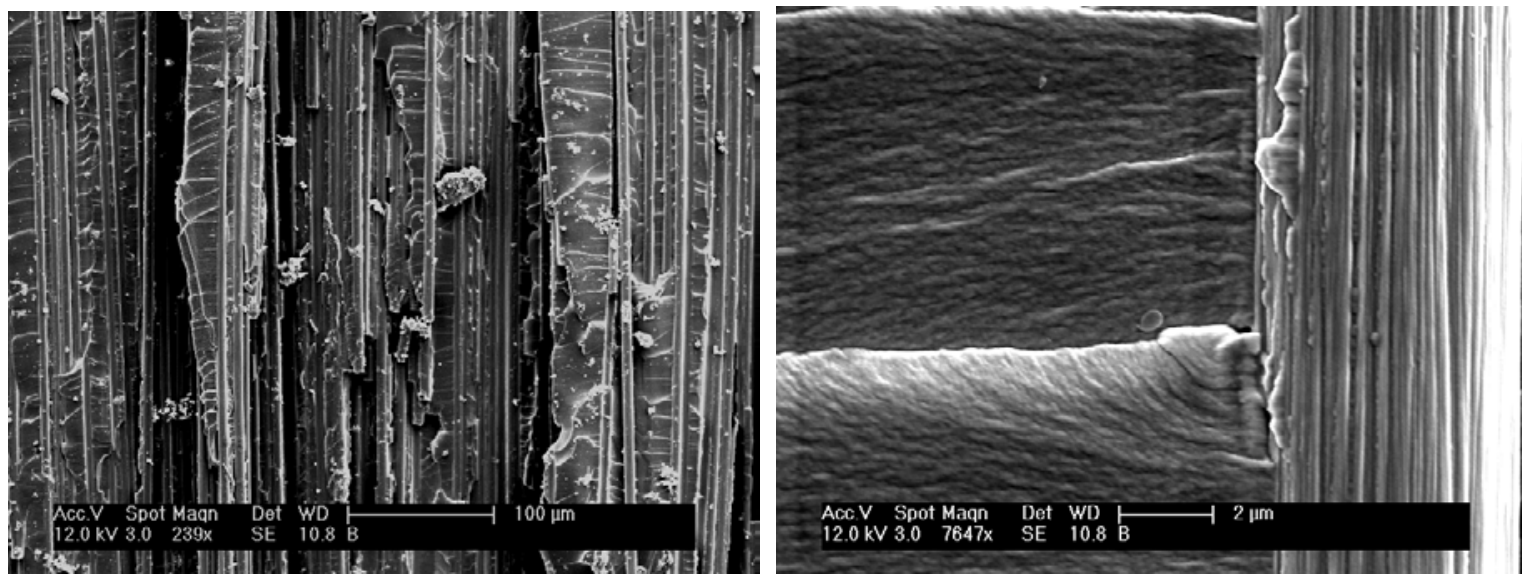

Composite B
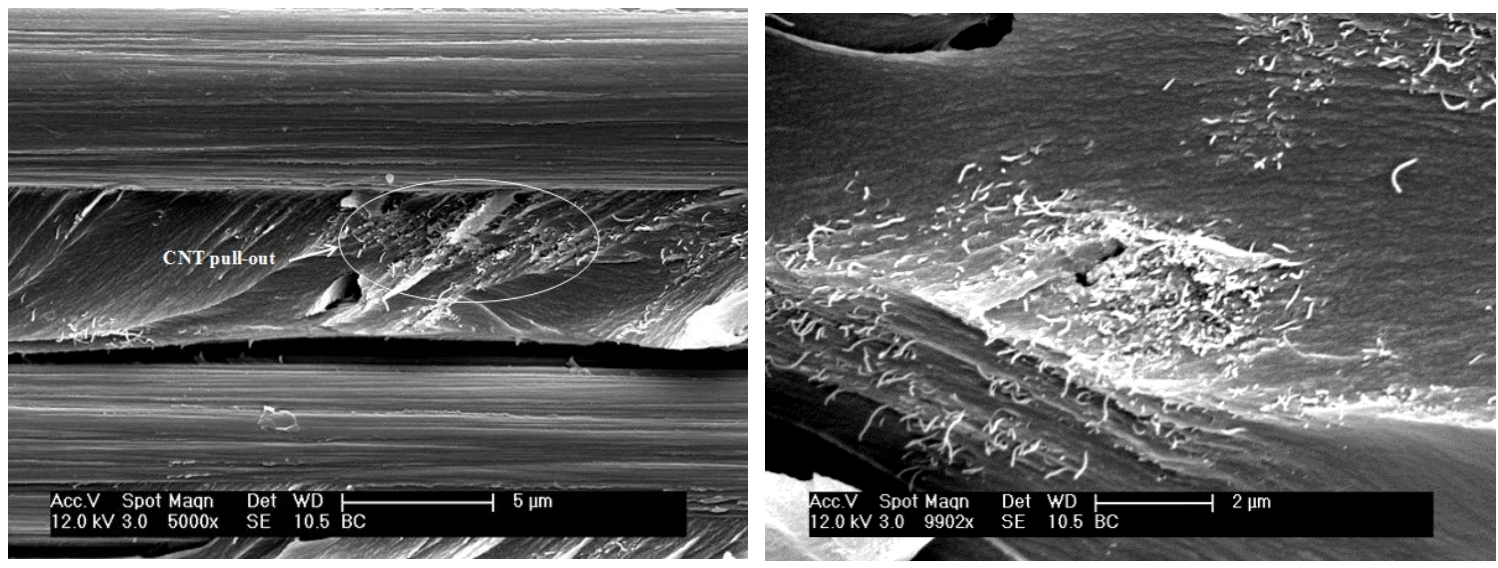

Composite BC

Figure 10 Typical SEM micrographs of fracture surfaces of the 4 ENF specimens for composites produced using a) as-received fabric (A) and two types of coated fabrics: curable binder (B); 1 wt.\% MWCNTs in curable binder (BC).

An increase in interfacial bonding between the CF and matrix for the B composite is proposed to be a major factor in the increase in its $\mathrm{G}_{\text {IIC-prop }}$ over the A composite. For example, Madukar and Drazal [22] showed $\mathrm{G}_{\text {IIC }}$ to increase by a factor up to 2.9 upon increasing fibre-matrix adhesion in epoxy-CF composites by surface treatment of the as-produced CF; the increase being ascribed to the initiation of energy-absorbing mechanisms 
such as matrix deformation and fibre pull-out. In the current study, the multiphase matrix generated by RIPS on addition of the binder is another factor in the increase of the mode II ILFT of composite B. The formation of a multiphase structure introduces potential additional energy absorbtion mechanisms to the matrix such as deflection of the crack, deformation of the secondary-phase particles or microcracking and makes it more difficult for cracks to propagate [20]. For example, the effects of an epoxy-thermoplastic multiphase matrix formed by RIPS were studied by Wu et al [16]. Composites reinforced with a uniweave unidirectional CF fabric, un-coated and coated with a poly(aryletherketone), PAEK, were prepared using RTM6-2 as the matrix. Composites with a PAEK-toughened matrix showed a 4 fold increase in mode II ILFT compared to the composite with the unmodified matrix, resulting from the formation of a tough multiphase matrix in the interlaminar regions due to the PAEK coating on the CF fabric.

\section{Conclusions}

Multi-scale composites were prepared using CF fabric spread-coated with an epoxy resin binder containing up to 1 wt.\% MWCNTs. The simple coating process used was quick and easy but also increased the resistance to compression of the CF tows. This resulted in lower packing fractions during vacuum-only RI and required the use of a hybrid RI/hot-press moulding technique with significant overpressure capability to compress the coated fabrics. The uncured binder and matrix epoxy system formed a multiphase matrix due to reaction-induced phase separation (RIPS) which increased values of $\mathrm{G}_{\text {IC-Prop }}$ and $\mathrm{G}_{\text {IIC-Prop }}$ ILFT by up to 110 and 57\%, respectively, but also caused significant plasticisation of the matrix and reduced the main $\mathrm{T}_{\mathrm{g}}$ (as measured by the drop in dynamic storage modulus) by up to $45^{\circ} \mathrm{C}$. This plastication was addressed to a degree by crosslinking of the binder, which also increased $\mathrm{G}_{\text {IC-Prop }}$ ILFT by $87 \%$ and $\mathrm{G}_{\text {IIC-Prop }}$ by $40 \%$. However, it was the combination of cured binder with 1 wt.\% MWCNTs that gave the highest increases in ILFT; $234 \%$ in G $_{\text {IC-Prop }}$ and 106\% in G IIC-Prop $_{\text {. }}$ The addition of MWCNTs also inhibited the plasticisation of the matrix, reducing the drop in $\mathrm{T}_{\mathrm{g}}$ to approximately $25^{\circ} \mathrm{C}$, but DMTA showed there was still a marked reduction in storage modulus compared to composite A across the full experimental temperature range. Thus, whilst the simple spread-coating process used provided a quick and easy nanoparticle modification of CF fabric reinforcement to produced multi-scale composites with reinforced CF-matrix interfaces, the plasticisation of the matrix by the binder must be inhibited. Approaches such as addition of higher levels ( $>1 \mathrm{wt} . \%$ ) of MWCNTs, treating the nanotubes to improve their interfacial adhesion with the binder, curing the binder before composite processing and the use of higher $\mathrm{T}_{\mathrm{g}}$ epoxy binders to coat the fabrics may address this problem.

\section{References}

[1] Qian H, Greenhalgh ES, Shaffer MSP, Bismarck A. Carbon nanotube-based hierarchical composites: a review, Journal of Materials Chemistry 2010, 20: 4751-4762.

[2] Wicks SS, de Villoria RG, Wardle BL, Interlaminar and intralaminar reinforcement of composite laminates with aligned carbon nanotubes, Compos. Sci. Technol. 2010, 70(1): 20-28.

[3] Frømyr TR, Hansen FK, Olsen T, The optimum dispersion of carbon nanotubes for epoxy nanocomposites: evolution of the particle size distribution by ultrasonic treatment, J. Nanotechnol. 2012, vol. 2012: 1-14.

[4] Ma P-C, Mo S-Y, Tang B-Z, Kim J-K, Dispersion, interfacial interaction and re-agglomeration of functionalized carbon nanotubes in epoxy composites, Carbon 2010, 48(6):1824-34. 
[5] Godara A, Mezzo L, Luizia F, Warrier A, Lomov SV, van Vuure, L. Gorbatikh L, Moldenaers P, Verpoest I, Influence of carbon nanotube reinforcement on the processing and the mechanical behaviour of carbon fiber/epoxy composites, Carbon 2009, 47: 2914-2923.

[6] Wilkinson AN, Kinloch IA, Othman RN, Low viscosity processing using hybrid CNT-coated silica particles to form electrically conductive epoxy resin composites, Polymer 2016, 98: 32-38.

[7] Gojny FH, Wichmann MHG, Fiedler B, Bauhofer W, Schulte K, Influence of nano-modification on the mechanical and electrical properties of conventional fibre-reinforced composites, Composites Part A, 2005, 36: 1525-1535.

[8] Kepple KL, Sanborn GP, Lacasse PA, Gruenberg KM, Ready WJ, Improved fracture toughness of carbon fiber composite functionalized with multi walled carbon nanotubes, Carbon 2008, 46(15): 2026-2033.

[9] Zhang H, Liu Y, Kuwata M, Bilotti E, Peijs T, Improved fracture toughness and integrated damage sensing capability by spray coated CNTs on carbon fibre prepreg, Composites Part A 2015, 70: 102-110.

[10] Herceg TM, Abidin MSZ, Greenhalgh ES, Shaffer MSP, Bismarck A, Thermosetting hierarchical composites with high carbon nanotube loadings: en route to high performance Compos. Sci. Technol. 2016, 127, :134-141.

[11] Liu Y, Wilkinson A, Rheological percolation behaviour and fracture properties of nanocomposites of MWCNTs and a highly crosslinked aerospace-grade epoxy resin system, Composites Part A 2018, 105: 97-107.

[12] Aktas L, Altan MC, Characterization of nanocomposite laminates fabricated from aqueous dispersion of nanoclay, Polymer Composites 2010, 31: 620-629.

[13] ASTM D5528-13 Standard Test Method for Mode I Interlaminar Fracture Toughness of Unidirectional Fiber-Reinforced Polymer Matrix Composites 1, 2014.

[14] Kuwata M, Hogg PJ. Interlaminar toughness of interleaved CFRP using non-woven veils: part 2. modeII testing, Composites Part A 2011, 42(10): 1560-1570.

[15] Lomov SV, Gorbatikh L, Kotanjac Ž, Koissin V, Houlle M, Rochez O, Karahan M, Mezzo L, Verpoest I, Compressibility of carbon woven fabrics with carbon nanotubes/nanofibres grown on the fibres, Compos. Sci. Technol. 2011, 71: 315-325.

[16] Wu Z, Yi X-S, Wilkinson A. Interlaminar fracture toughness of carbon fibre/RTM6-2 composites toughened with thermoplastic-coated fabric reinforcement, Composites Part B 2017, 130: 192-199.

[17] Drzal LT, Rich MJ, Koenig MF, Lloyd PF, Adhesion of graphite fibers to epoxy matrices: II: the fffect of fiber finish, The Journal of Adhesion 1983, 16:133-152.

[18] Williams RJJ, Rozenberg BA, Pascault J-P, Reaction-induced phase separation in modified thermosetting polymers, Advances in Polymer Science 1997, 128:95-156.

[19] Kuwata M, Hogg PJ. Interlaminar toughness of interleaved CFRP using non-woven veils: part 1. mode-I testing, Composites Part A 2011, 42(10): 1551-1559.

[20] Pearson RA, Yee AF, Toughening mechanisms in thermoplastic modified epoxies: 1. modification using poly (phenylene oxide), Polymer 1993, 34: 3658-3670.

[21] Hsieh TH, Kinloch AJ, Taylor AC, Kinloch IA, The effect of carbon nanotubes on the fracture toughness and fatigue performance of a thermosetting epoxy polymer. J Mater Sci. 2011, 46(23): 7525-7535. 
[22] Madhukar MS, Drzal LT, Fiber-matrix adhesion and its effect on composite mechanical properties: IV. Mode I and Mode II fracture toughness of graphite/epoxy composites, J. Compos. Mater. 1992, 26(7): 936-968. 